\title{
Raised intracranial pressure and cerebral blood flow

\author{
3. Venous outflow tract pressures and vascular resistances in \\ experimental intracranial hypertension
}

\author{
I. H. JOHNSTON AND J. O. ROWAN \\ From the Medical Research Council Cerebral Circulation Research Group at the Institute of Neurological \\ Sciences, Glasgow, and the Wellcome Surgical Research Institute, University of Glasgow
}

SYNOPSIS Pressure changes within the venous outflow tract from the brain were studied in anaesthetized baboons. Segmental vascular resistance changes were also calculated and the results correlated with the changes in cerebral blood flow, measured by the ${ }^{133}$ Xenon clearance method. Three different methods were used to raise intracranial pressure: cisterna magna infusion, a supratentorial subdural balloon, and an infratentorial subdural balloon. A close correlation was found between the cortical vein pressure and intracranial pressure with all methods of raising intracranial pressure: the overall correlation coefficient was 0.98 . In the majority of animals sagittal sinus pressure showed little change through a wide range of intracranial pressure. In three of the six animals in the cisterna magna infusion group, however, sagittal sinus pressure increased to levels approaching the intracranial pressure during the later stages of intracranial hypertension. Jugulag venous pressure showed little change with increasing intracranial pressure. The relationship betweep $\vec{D}$ cerebral perfusion pressure and cerebral blood flow differed according to the method of increasing intracranial pressure. This was due to differing patterns of change in prevenous vascular resistance a\& venous resistance increased progressively with increasing pressure in all three groups. The presen results confirm, therefore, the validity of the current definition of cerebral perfusion pressure-that is

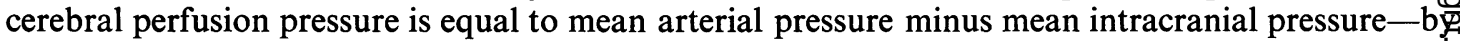
demonstrating that intracranial pressure does represent the effective cerebral venous outflow pressure.

Raised intracranial pressure is known to cause a reduction in cerebral blood flow, although the quantitative aspects of the relationship remain poorly defined. Attempts have been made to establish a correlation between perfusion pressure and blood flow and to identify critical levels of perfusion pressure below which blood flow begins to fall (Zwetnow, 1968, 1970). Both clinical and experimental observations have, however, shown that no such direct relationship exists (Miller et al., 1972; Johnston et al., 1972, 1973). This may reflect the inadequacy of the present definition of cerebral perfusion pressure or dependence of the nature of vascular resistance changes on the type of increase in intracranial pressure.

The aim of the present study has been to measure directly the pressure changes occurring in different segments of the venous outflow tract from the brain when the intracranial pressure is raised in various ways. Thus the validity of the definition of cerebral perfusion pressure as mean arterial pressure minus mean intracranial pressure can be examined by determining whether intracranial pressure accurately represents the effective venous outflow pressure in different circumstances. At the same time, the changes in vascular resistance can be calculated and the nature of these changes related to the varying effect on cerebral blood flow of the different forms of intracranial hypertension seen in the earlier studies.

\section{METHODS}

Thirteen baboons, weighing between 8 and $13 \mathrm{~kg}$, were used. Anaesthesia was induced with phencyclidine hydrochloride (10 mg intramuscularly) and thiopentone sodium (60 mg intramuscularly) and maintained with phencyclidine hydrochloride and nitrous oxide/oxygen mixture. The animals were 
paralysed with suxamethonium chloride and ventilation was controlled using a Starling pump delivering a tidal volume adjusted according to end-tidal $\mathrm{CO}_{2}$ and arterial blood gas levels.

The following parameters were measured:

CEREBRAL BLOOD FLOW (CBF) A polyethylene cannula was placed in the proximal stump of the right lingual artery after ligation of the right external carotid artery. Serial measurements of blood flow were made using a slug injection of the radioisotope ${ }^{133}$ Xenon dissolved in 0.45 to $0.55 \mathrm{ml} .0 .9 \%$ saline at $37 \cdot 4^{\circ} \mathrm{C}$. The rate of clearance of gamma activity was monitored using a collimated $1 \mathrm{in}$. sodium iodide crystal scintillation detector placed over the right parietal region. Cerebral blood flow was calculated both from the initial slope of the clearance curve and from the ratio of peak height to the area under the curve. In addition, carotid artery blood flow was monitored continuously, using an electromagnetic flow probe of 2.5 to $3.5 \mathrm{~mm}$ diameter (Nycotron) on the exposed right common carotid artery.

VENOUS OUTFLOW TRACT PRESSURES The following pressures were measured continuously by means of indwelling catheters inserted as described below and connected to strain gauge transducers.

Cortical vein pressure (CoVP) A small craniectomy, extending from the midline immediately behind the coronal suture was made on the right side. A dural flap was reflected, hinged medially, to expose one of the large cortical veins in the area of entry into the superior sagittal sinus. Using the Zeiss operating microscope the vein was freed of arachnoid membrane for 1-2 mm, a small incision was made in the vein wall, and a fine polyethylene catheter inserted for a distance of 1-2 cm, directed away from the midline. The placement of the catheter in the vein was checked by irrigating with small volumes of $0.9 \%$ saline under vision and also by observing backflow of venous blood into the catheter. The catheter was secured to the dura mater with a suture and to the cranium with dental cement. The dural incision was closed around the catheter with a continuous suture.

Superior sagittal sinus pressure (SSP) A fine polyethylene catheter was inserted into the superior sagittal sinus through a needle puncture $2 \mathrm{~cm}$ behind the bregma and the catheter threaded a further $2 \mathrm{~cm}$ along the sinus towards the torcular.

Jugular bulb pressure (JVP) A polyethylene catheter was inserted in retrograde fashion, into the jugular bulb from the exposed internal jugular vein in the neck.

The craniectomy defect was sealed using dental cement.

OTHER PARAMETERS Ventricular fluid pressure (VFP) was measured using a polyethylene cannula inserted into the frontal horn of the right lateral ventricle via a twist drill hole on the coronal suture $1 \mathrm{~cm}$ lateral to the bregma.

Cisterna magna pressure (CMP) was measured in some experiments using a polyethylene cannula inserted by puncture of the atlantooccipital membrane under direct vision.

Arterial blood pressure (BP) was measured from the catheter in the right lingual artery. In some experiments, when a poor tracing was obtained from this catheter due to damping, arterial pressure was measured from a catheter inserted into the abdominal aorta via the left femoral artery.

End tidal $\mathrm{CO}_{2}$ was continuously monitored using an infrared analyser (Capnograph).

Arterial blood gases $\left(\mathrm{pO}_{2}, \mathrm{pCO}_{2}\right.$, and $\left.\mathrm{pH}\right)$ were estimated at frequent intervals, as were sagittal sinus $\mathrm{pO}_{2}$ and $\mathrm{pH}$, using direct reading electrodes (Radiometer).

Venous $\mathrm{PCV}$ and $\mathrm{Hb}$ were estimated at frequent intervals.

Intracranial pressure was raised in one of three different ways: (1) by infusion of mock cerebrospinal fluid (CSF), at constant temperature, into the cisterna magna (six animals); (2) by expansion of a supratentorial subdural balloon in the right parietal region (six animals); and (3) by expansion of an infratentorial subdural balloon in the right cerebellopontine angle (one animal). In each group of experiments the pressure was raised in increments of 10-20 $\mathrm{mmHg}$ at approximately 30 minute intervals.

\section{RESULTS}

PRESSURE CHANGES Cortical vein pressure The mean control values for all measured variables are shown in Table 1. With infusion of fluid into the cisterna magna, cortical vein pressure rose progressively with increasing intracranial pressure up to extreme levels of intracranial hypertension. The linearity of the relationship is shown in Fig. 1a in which cortical vein pressures are plotted against intracranial pressures for all 
TABLE 1

MEAN CONTROL VALUES AND MEAN VALUES AT MAXIMUM INTRACRANIAL PRESSURE IN EACH OF THE THREE GROUPS

\begin{tabular}{|c|c|c|c|c|c|c|c|}
\hline & $I C P$ & CoVP & $S S P$ & $J V P$ & $\boldsymbol{B P}$ & $C P P$ & $C B F$ \\
\hline $\begin{array}{l}\text { Cisterna magna infusion } \\
\text { Control } \\
\text { At max. ICP }\end{array}$ & $\begin{array}{r}9 \cdot 1 \\
114 \cdot 3\end{array}$ & $\begin{array}{r}11.4 \\
113.4\end{array}$ & $\begin{array}{r}4 \cdot 8 \\
43 \cdot 6\end{array}$ & $\begin{array}{l}3 \cdot 6 \\
6 \cdot 3\end{array}$ & $\begin{array}{r}90 \cdot 7 \\
129.7\end{array}$ & $\begin{array}{l}81 \cdot 8 \\
15 \cdot 0\end{array}$ & $\begin{array}{l}41 \cdot 5 \\
11 \cdot 5\end{array}$ \\
\hline $\begin{array}{l}\text { Supratentorial balloon } \\
\text { Control } \\
\text { At max. ICP }\end{array}$ & $\begin{array}{r}5 \cdot 6 \\
74 \cdot 3\end{array}$ & $\begin{array}{r}9 \cdot 1 \\
77 \cdot 7\end{array}$ & $\begin{array}{r}8 \cdot 3 \\
11 \cdot 2\end{array}$ & $\begin{array}{l}4 \cdot 5 \\
3 \cdot 8\end{array}$ & $\begin{array}{l}71 \cdot 2 \\
91 \cdot 3\end{array}$ & $\begin{array}{l}64 \cdot 2 \\
17 \cdot 0\end{array}$ & $\begin{array}{l}49.0 \\
15.0\end{array}$ \\
\hline $\begin{array}{l}\text { Infratentorial balloon } \\
\text { Control } \\
\text { At max. ICP }\end{array}$ & $\begin{array}{l}11 \cdot 7 \\
47 \cdot 0\end{array}$ & $\begin{array}{l}17 \cdot 0 \\
51 \cdot 0\end{array}$ & - & - & $\begin{array}{r}75.3 \\
133.0\end{array}$ & $\begin{array}{l}63 \cdot 7 \\
86 \cdot 0\end{array}$ & $\begin{array}{l}38 \cdot 9 \\
66 \cdot 0\end{array}$ \\
\hline
\end{tabular}

(All values in $\mathrm{mmHg}$ except $\mathrm{CBF}, \mathrm{ml} / 100 \mathrm{~g} / \mathrm{min}$.)

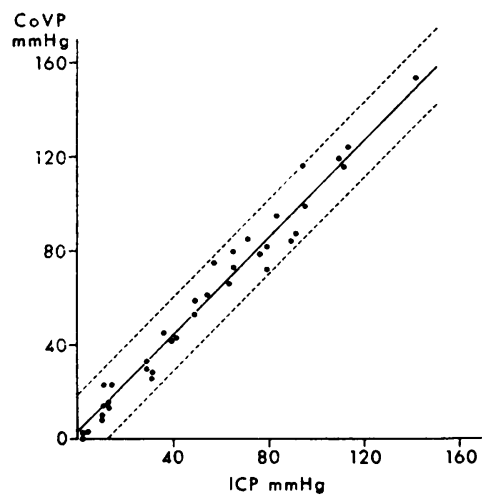

(a)



(b)



(c)

FIG. 1. Cortical vein pressures during increased intracranial pressure. (a) Cisterna magna infusion. (b) Supratentorial subdural balloon. (c) Infratentorial subdural balloon. Data from all experiments in each group.

TABLE 2

SUMMARY OF CORRELATIONS BETWEEN CORTICAL VEIN PRESSURE AND INTRACRANIAL PRESSURE FOR EACH METHOD OF RAISING INTRACRANIAL PRESSURE

\begin{tabular}{|c|c|c|c|c|c|c|}
\hline $\begin{array}{l}\text { Type of ICP } \\
\text { increase }\end{array}$ & $\begin{array}{l}\text { Regression } \\
\text { equation }\end{array}$ & $\begin{array}{c}\text { Correla- } \\
\text { tion } \\
\text { coefficient }\end{array}$ & $t$ & $p$ & $S y$ & $n$ \\
\hline $\begin{array}{l}\text { Cisterna } \\
\text { magna } \\
\text { infusion } \\
\text { Supratentorial }\end{array}$ & $y=1 \cdot 03 x+2 \cdot 8$ & 0.98 & 32 & $\ll 0.001$ & 7.95 & 39 \\
\hline & $y=0.905 x+2.7$ & 0.97 & 22 & $\ll 0.001$ & 6.58 & 33 \\
\hline $\begin{array}{l}\text { balloon } \\
\text { All }\end{array}$ & $\begin{array}{l}y=0.89 x+6.9 \\
y=0.997 x+2.5\end{array}$ & $\begin{array}{l}0.96 \\
0.98\end{array}$ & $\begin{array}{l}10 \\
41\end{array}$ & $\begin{array}{l}\ll 0.001 \\
\ll 0.001\end{array}$ & $\begin{array}{l}2 \cdot 88 \\
6 \cdot 75\end{array}$ & $\begin{array}{l}14 \\
86\end{array}$ \\
\hline
\end{tabular}

simultaneous measurements of the two pressures in the cisterna magna infusion experiments. The correlation coefficient, 0.98 , is highly significant and the regression line closely parallel to the line of identity. The positive intercept on the cortical venous pressure axis, at $2.8 \mathrm{mmHg}$, reflects the tendency of vein pressure to remain slightly higher than intracranial pressure. A similar, linear, relationship between cortical vein pressure and intracranial pressure was also seen when the latter was increased by expansion of either a supratentorial or infratentorial balloon (Figs 1b, c). The data from all three methods of increasing intracranial pressure are summarized 


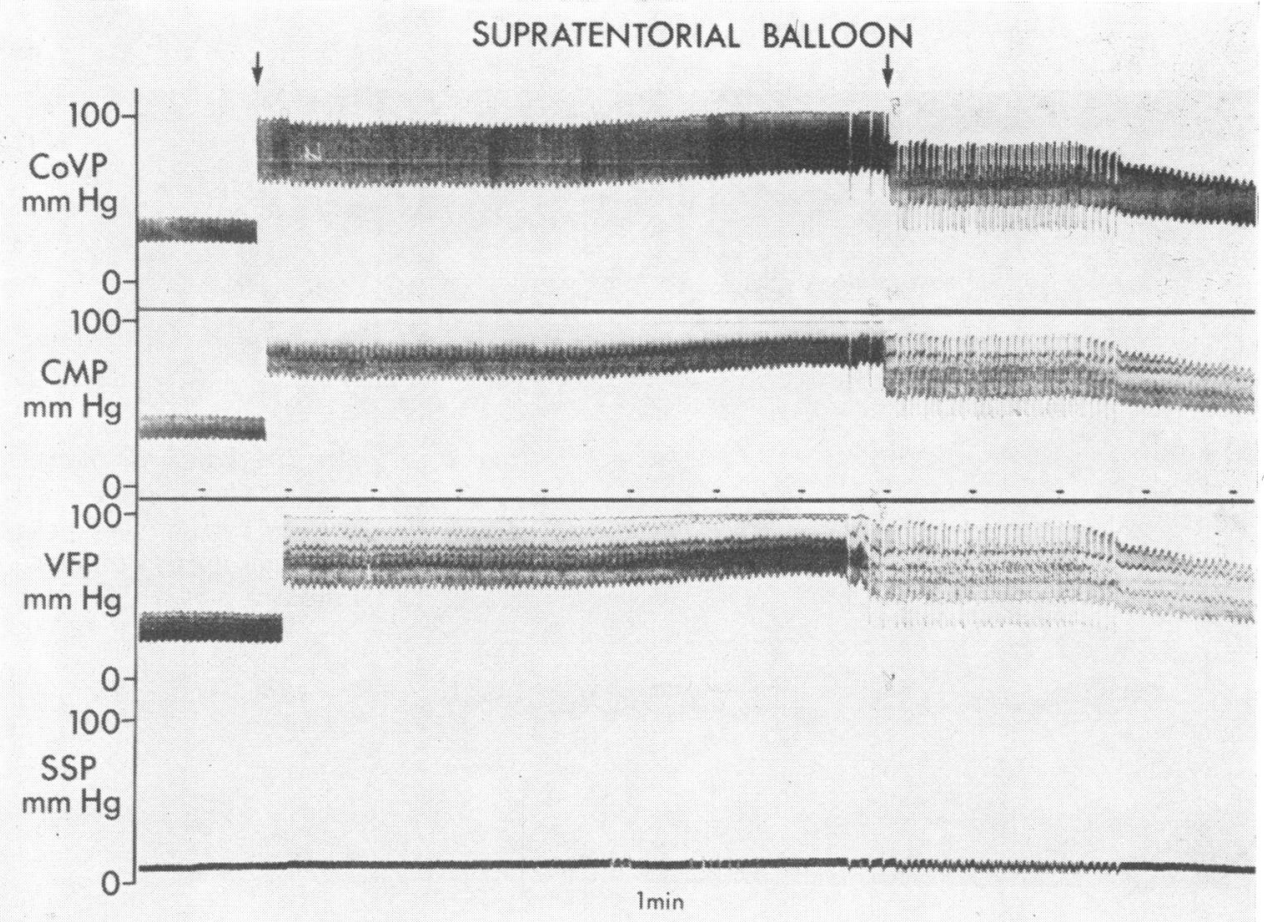

FIG. 2. Correspondence of transient changes in cortical vein pressure and intracranial pressure (supratentorial balloon). First arrow indicates balloon expansion, second arrow indicates range change on recorder to $120-20 \mathrm{mmHg}$.

in Table 2. Transient induced changes in intracranial pressure were also closely mirrored by similar changes in cortical vein pressure (Fig. 2).

A positive pressure gradient existed between cortical vein and superior sagittal sinus under control conditions. This gradient increased progressively with all methods of raising intracranial pressure, although the magnitude of the increase was much less in three animals in the cisterna magna infusion group in which a progressive rise in sagittal sinus pressure occurred. In these animals sinus pressure rose to the level of cortical vein pressure for a short time, during the later stages of intracranial hypertension.

Superior sagittal sinus pressure Mean control values for all three groups are given in Table 1 . With cisterna magna infusion two distinct types of response were seen. In three out of six animals sagittal sinus pressure rose only slightly as the intracranial pressure was raised to levels of approximately $40 \mathrm{mmHg}$. At this point sagittal sinus pressure began to rise rapidly and progressively as intracranial pressure was further increased to reach maximum levels of 60,80 , and $118 \mathrm{mmHg}$ at intracranial pressure levels of 94, 112 , and $111 \mathrm{mmHg}$ respectively. In these three animals, during the later stages of intracranial hypertension, transient changes in sagittal sinus pressure were also seen. These changes were often of considerable magnitude and were apparently independent of changes in any of the other measured variables (Fig. 3). In the other three animals in the cisterna magna infusion group sagittal sinus pressure remained low throughout and, although there was a slight rise during the later stages of intracranial hypertension levels, the pressure always remained less than $20 \mathrm{mmHg}$. Small fluctuations in sinus pressure in these three animals were predomi- 




FIG. 3. Transient changes in sagittal sinus pressure occurring without corresponding changes in other parameters (cisterna magna infusion).



(a)

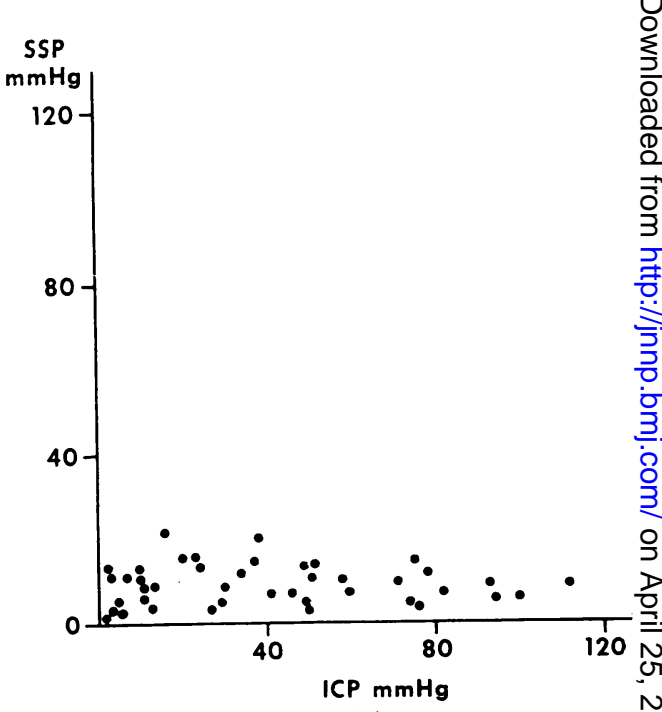

(b)

FIG. 4. Sagittal sinus pressures during increased intracranial pressure. (a) Cisterna magna infusion. (b) Supratentorial subdural balloon. Data from all experiments in each group. 
nantly reflections of changes in cerebral blood flow as shown by the carotid artery flowmeter. The two different patterns of response are apparent from Fig. 4a, which is a summary of all simultaneous measurements of sagittal sinus and intracranial pressure in the cisterna magna infusion experiments.

When intracranial pressure was raised by expansion of either a supratentorial or an infratentorial subdural balloon, sagittal sinus pressure remained low throughout (Fig. 4b). In addition, there were no transient, apparently spontaneous, changes in sagittal sinus pressure of the type seen with cisterna magna infusion.

A substantial gradient between sagittal sinus and jugular bulb pressures was seen only in those animals showing a marked increase in sagittal sinus pressure during the later stages of intracranial hypertension.

Jugular bulb pressure Mean control values are shown in Table 1. With cisterna magna infusion there was a slight but progressive increase in jugular bulb pressure as intracranial pressure was increased. In the later stages of each experiment, however, jugular bulb pressure fell as both arterial blood pressure and cerebral blood flow fell. With expansion of either a supratentorial or infratentorial balloon, there was little change in jugular bulb pressure with increasing intracranial pressure: some animals showed a slight increase, others a slight decrease.

\section{Blood pressure and cerebral perfusion pressure} With cisterna magna infusion all animals showed a marked increase in blood pressure, starting during the initial stages of intracranial hypertension, reaching a maximum at intracranial pressure levels between 40 and $90 \mathrm{mmHg}$, then falling as intracranial pressure was further increased. Likewise, with both types of balloon there was a blood pressure response, a transient response occurring with each addition of fluid to the balloon, in addition to a sustained increase over the course of each experiment. The magnitude of the sustained response was, however, less than with cisterna magna infusion.

Changes in cerebral perfusion pressure, whether calculated as the difference between blood pressure and cortical vein pressure, or between blood pressure and jugular bulb pres- sure depended largely on the time of onset and magnitude of the blood pressure response. With cisterna magna infusion cerebral perfusion pressure (blood pressure-cortical vein pressure) rose steadily in three of the six animals, reached a maximum at intracranial pressure levels of 36 , 49 , and $65 \mathrm{mmHg}$ respectively, then fell progressively as the intracranial pressure was further increased. In the other three animals in this group there was an early fall in cerebral perfusion pressure, at intracranial pressure levels of 25,29 , and $41 \mathrm{mmHg}$, after which perfusion pressure returned to approximately control levels as intracranial pressure was further increased. In all six experiments in this group cerebral perfusion pressure fell in the later stages, as the blood pressure fell progressively.

With the supratentorial subdural balloon changes in cerebral perfusion pressure (blood pressure - cortical vein pressure) were more uniform. Values remained around control levels up to intracranial pressure levels from 38-93 $\mathrm{mmHg}$, then fell as intracranial pressure was increased beyond these levels. There was no range of intracranial pressure during which perfusion pressure tended to be greater than control levels.

If cerebral perfusion pressure was calculated as the difference between blood pressure and jugular bulb pressure, there was also a different response according to the way in which intracranial pressure was increased. With cisterna magna infusion perfusion pressure increased with the initial increases in intracranial pressure, then remained well above control levels as intracranial pressure was further increased. With the supratentorial balloon there was also an initial increase in perfusion pressure of smaller magnitude, after which perfusion pressure remained within a relatively narrow range, only slightly greater than the control range, as intracranial pressure was further increased.

RESISTANCE CHANGES When cerebrovascular resistance was calculated as the ratio of cerebral perfusion pressure to cerebral blood flow there was considerable variation in the changes in the cisterna magna infusion group. In two of the six animals cerebrovascular resistance fell progressively with increasing intracranial pressure. In the remaining four animals the level of vascular resistance varied considerably. The different 



(a)

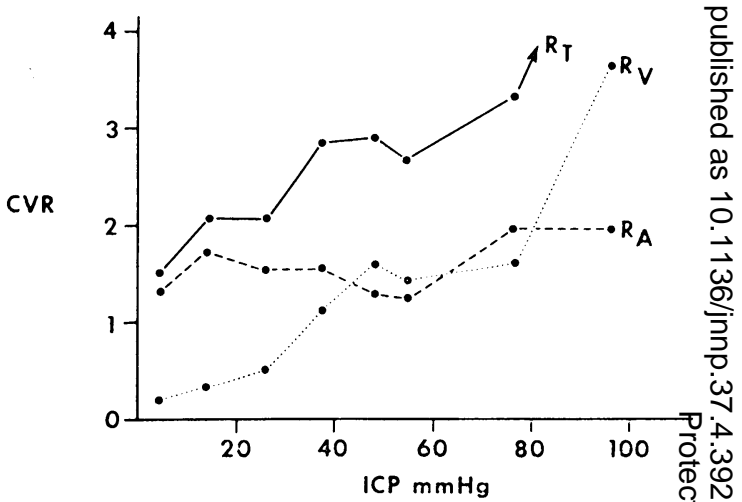

(b)

FIG. 5. Mean values for cerebral perfusion pressure (CPP), cerebral blood flow (CBF) and segmental vasculv resistance (total resistance $\mathrm{Rt}$, arterial resistance $\mathrm{Ra}$, and venous resistance $\mathrm{Rv}$ ), for $10 \mathrm{mmHg}$ ranges \& intracranial pressure. (a) Cisterna magna infusion. (b) Supratentorial subdural balloon.

patterns of response did not coincide with differences in the blood flow response, although the two animals showing a progressive fall in cerebrovascular resistance were those in whom the superior sagittal sinus pressure remained low throughout.

With the supratentorial subdural balloon, changes in cerebrovascular resistance were more uniform, five of the six animals showing an initially steady level, followed by a slight, but progressive fall. In the sixth animal vascular resistance started to fall with the first increase in intracranial pressure, but then rose slightly towards the end of the experiment.

When arterial and venous resistances were calculated separately a more uniform picture emerged. With cisterna magna infusion all animals showed a progressive increase in venous resistance with increasing intracranial pressure (Fig. 5a). In three of the six animals, the major locus of venous resistance remained between cortical vein and sagittal sinus, whereas in the other three animals the main venous resistance shifted to the sagittal sinus during the latter stages of intracranial hypertension. In all six animals the arterial resistance tended to fall progressively (Fig. 5a).

With the supratentorial subdural balloon a different type of response was seen. Whereas a progressive increase in venous resistance, similar to that seen with cisterna magna infusion, did occur (Fig. 5b), the major locus of resistance remained between the cortical veins and the sagittal sinus in all instances. The main contrast was, however, provided by the arterial resistance which showed much less tendency to fall with increasing intracranial pressure when compared with the cisterna magna infusion group (Fig. 5b).

BLOOD FLOW CHANGES Control values for each group are shown in Table 1 . The basic patterns of response were similar to those described in detail in the earlier studies (Johnston et al., 1972, 1973). In addition, the relationships between 
TABLE 3

VALUES FOR CEREBRAL BLOOD FLOW (CBF), CEREBRAL PERFUSION PRESSURE (CPP), AND SEGMENTAL VASCULAR RESISTANCE, AT CONTROL LEVELS AND AT MAXIMUM CEREBRAL BLOOD FLOW, FOR INDIVIDUAL EXPERIMENTS IN CISTERNA MAGNA INFUSION GROUP

\begin{tabular}{|c|c|c|c|c|c|c|c|c|c|c|}
\hline Expt. & $\begin{array}{c}C B F \\
(\mathrm{ml} . / 100 \mathrm{~g} / \mathrm{min})\end{array}$ & $\begin{array}{c}C P P \\
(m m H g)\end{array}$ & $R_{t}$ & $\boldsymbol{R}_{a}$ & $R v$ & $\begin{array}{c}C B F \\
(\mathrm{ml} . / 100 \mathrm{~g} / \mathrm{min})\end{array}$ & $\begin{array}{c}C P P \\
(m m H g)\end{array}$ & $R_{t}$ & $\boldsymbol{R}_{a}$ & $R v$ \\
\hline 1 & 28 & 72 & $2 \cdot 88$ & $2 \cdot 44$ & 0.40 & 39 & 76 & $2 \cdot 56$ & $1 \cdot 82$ & 0.74 \\
\hline 2 & 46 & 79 & $1 \cdot 86$ & $1 \cdot 74$ & $0 \cdot 12$ & 61 & 98 & $2 \cdot 54$ & 1.47 & 1.07 \\
\hline 3 & 42 & 66 & $1 \cdot 73$ & $1 \cdot 52$ & $0 \cdot 21$ & 71 & 103 & $2 \cdot 21$ & $1 \cdot 24$ & 0.97 \\
\hline 4 & 56 & 99 & 1.90 & $1 \cdot 55$ & 0.35 & 83 & 98 & 1.80 & 0.96 & 0.84 \\
\hline 5 & 45 & 84 & 1.91 & $1 \cdot 87$ & 0.04 & 55 & 121 & 3.01 & $2 \cdot 12$ & 0.89 \\
\hline 6 & 39 & 87 & $2 \cdot 22$ & - & - & 110 & 81 & 0.74 & - & - \\
\hline Mean & $42 \cdot 7$ & $81 \cdot 2$ & $2 \cdot 08$ & $1 \cdot 82$ & 0.22 & $69 \cdot 8$ & $96 \cdot 2$ & $2 \cdot 14$ & $1 \cdot 52$ & 0.90 \\
\hline SD & $9 \cdot 2$ & $11 \cdot 65$ & 0.42 & 0.37 & $0 \cdot 15$ & $24 \cdot 6$ & $16 \cdot 2$ & 0.80 & 0.46 & 0.13 \\
\hline
\end{tabular}

blood flow and perfusion pressure (blood pressure minus cortical vein pressure) were the same as those described earlier, there being a different relationship with each method of raising the intracranial pressure. The period of hyperaemia seen with cisterna magna infusion was associated in three out of six animals, with an increase in cerebral perfusion pressure. In two of these three animals arterial resistance fell slightly, while in the others it increased. In the other three animals in this group cerebral perfusion pressure was at approximately control levels at the time of maximum hyperaemia which was associated with a marked fall in arterial resistance (Table 3 ).

\section{DISCUSSION}

In trying to explain why different ways of raising intracranial pressure lead to different patterns of change in cerebral blood flow, and quite distinct relationships between cerebral perfusion pressure and blood flow, two factors are important. Firstly, it is necessary to examine the validity of the current concept of cerebral perfusion pressure. Secondly, the nature of the vascular resistance changes occurring in the different forms of intracranial hypertension must be more clearly understood. To meet these requirements, it was decided to extend the existing observation on intracranial venous outflow tract pressures, since direct measurements of cortical vein pressures had not been made over a wide range of intracranial pressure and observations on sagittal sinus pressure changes have been quite conflicting. Apart from elucidating the variability in blood flow changes referred to above, direct pressure measurements in various segments of the venous outflow tract might, it was thought, provide information about other aspects of brain function affected by raised intracranial pressure.

The present results clearly show that the pressure within the large cortical veins rises progressively with increasing intracranial pressure, in linear fashion, with vein pressures tending to remain at slightly higher levels than intracranial pressures. These findings are in accord with the earlier studies that cortical vein pressure in the lower ranges of intracranial pressure is increased (Shulman, 1965; Shulman and Verdier, 1967). A slight positive differential between the two pressures is, of course, essential in maintaining the patency of the veins.

The pressure within the posterior part of the superior sagittal sinus showed a less uniform response with progressive intracranial hypertension. With cisterna magna infusion a number of animals showed a considerable rise in sinus pressure, starting at intracranial pressure levels around $40 \mathrm{mmHg}$ and continuing as intracranial pressure was further increased. Other animals in the same group did not show this increase in sinus pressure, nor did any of the animals in the other two groups. Those animals in which sinus pressure rose markedly showed large transient fluctuations in pressure unrelated to changes in any of the other measured pressures. These have not been described previously and may represent intermittent opening and closing of the lumen of the sinus under the influence of the surrounding intracranial pressure.

In attempting to relate the present observa- 
tions on sagittal sinus pressure changes to previous findings it is difficult to achieve a satisfactory synthesis. Under normal conditions the pressure within the sinus would be expected to be less than the intracranial pressure and to depend largely on the right atrial pressure (Davson, 1967). This has been confirmed, both by direct measurement and by other methods (Wegefarth, 1914; Weed and Flexner, 1933; Bedford, 1942; Shulman et al., 1964). Observations during increased intracranial pressure have, however, given quite variable results. Some studies have shown little change in sagittal sinus pressure (Becht, 1920; Weed and Flexner, 1933), some have shown a decrease in sinus pressure (Wright, 1938; Bedford, 1942), while others have shown an increase in sagittal sinus pressure with increasing intracranial pressure (Dixon and Haliburton, 1914; Langfitt et al., 1966). Clinical measurements in acute intracranial hypertension and both clinical and experimental observations in chronic intracranial hypertension have also shown that sagittal sinus pressure may rise with increasing intracranial pressure (Shulman et al., 1964; Kinal, 1966; Osterholm, 1970). It seems probable that the pressure within the sagittal sinus reflects the sum of several variables including mechanical factors affecting sinus compressibility, the level of blood flow through the sinus, and the central venous pressure. The relative importance of each factor may, in turn, depend on the exact site of measurement, the species studied, and the method of increasing intracranial pressure which will act through differences both in local distorting forces and blood flow levels.

In the present study jugular bulb pressure showed little variation whatever method was used to raise intracranial pressure, findings which agree with earlier reports of both jugular bulb and torcular pressures (Bedford, 1942; Langfitt et al., 1966). Any changes which do occur in jugular bulb pressure will depend on a combination of changes in central venous pressure secondary to the effects of raised intracranial pressure on cardiovascular function (Brown, 1956) and on the level of cerebral blood flow.

Some of the main aspects of brain function which may be influenced by these changes in intracranial venous pressures include cerebral blood flow, capillary filtration, and $\mathrm{CSF}$ circulation.

Initial studies of cerebral blood flow in raised intracranial pressure attempted to relate levels of $\bar{\theta}$ blood flow directly to levels of intracranial of pressure (Kety et al., 1948; Noell and Schneider, §̊ 1948). More recently, cerebral perfusion pressure has been put forward as the major determinant of cerebral blood flow (Zwetnow, 1968; Häggendal et al., 1970; Zwetnow, 1970). If a clear relation between either intracranial pressure, or $\frac{}{0}$ cerebral perfusion pressure, and cerebral blood $\frac{\bar{\sigma}}{\bar{D}}$ flow could be established it would have obvious value for the clinician who, being able to measure these pressures, could predict what ${ }^{\text {s }}$ changes in cerebral blood flow might be occur- $\vec{\circ}$ ring in different clinical circumstances. Both $\vec{\omega}$ clinical and experimental studies, referred to $\stackrel{\sigma}{.}$ earlier (Miller et al., 1971; Johnston et al., 1972, 1973), have clearly shown, however, that no such direct relationship can be defined. This may be due both to the shortcomings of the present definition of cerebral perfusion pressure and the variable patterns of resistance change which may occur in different forms of intracrani hypertension.

The close correspondence between cortice्gl vein and intracranial pressures in the prese study establishes the validity of the assumption that intracranial pressure represents the effective venous outflow pressure through a wide range of intracranial pressure. Providing that there is no appreciable change in the magnitude of the

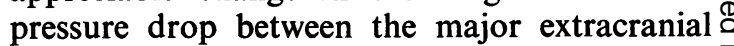
arteries and their intracranial extensions, the $\overline{0}$ present definition of cerebral perfusion pressure is acceptable (Kanzow and Dieckhoff, 1969). It is, therefore, to the different patterns of response of the intracranial vascular resistance that attention must be directed in an attempt to explain the variability of cerebral blood flow in different forms of intracranial hypertension.

With measurements of intravascular pressures at a series of points and assuming a uniformity 0 of flow through each section, it is possible to calculate segmental resistances for the blood vessels supplying and draining the brain. Such calculations show a progressive increase in venous resistance with increasing intracranial ${ }_{N}$ pressure with the major locus of resistance be- $\omega$ tween cortical veins and superior sagittal sinus. 
The uniformity of the direction of changes in venous resistance regardless of the method used to raise intracranial pressure suggests that it is differences in the prevenous resistance which determine the different patterns of change in cerebral blood flow. Calculated values support this view showing, for example, a marked fall in arterial resistance when intracranial pressure is raised by cisterna magna infusion, whereas with a supratentorial balloon arterial resistance tends to remain relatively high.

What is not clear, however, is how such differences in behaviour in the prevenous resistance vessels are brought about, although this is of central importance to an understanding of autoregulation in the cerebral circulation. Various theories have been proposed to explain autoregulation, metabolic, myogenic, neurogenic, and tissue pressure hypotheses (Green et al., 1964), yet the matter remains unresolved. The present studies do not permit any distinction between the extant theories. All that can be said is that, while changes in venous resistance appear to depend directly on the level of intracranial pressure, changes in prevenous resistance vary according to the way in which the intracranial pressure is increased.

Another factor which will clearly be influenced by alterations in cortical venous pressure is capillary filtration within brain tissue. The rate of net transcapillary fluid movement will depend on the factors originally defined by Starling, which include the hydrostatic capillary and interstitial fluid pressures, the colloid osmotic pressures of plasma and interstitial fluid, and the capillary filtration coefficient (Mellander and Johansson, 1968). The hydrostatic capillary pressure will, in turn, depend on arterial inflow and venous outflow pressures as well as the ratio between post and pre-capillary resistances (Pappenheimer and Soto-Rivera, 1948), while the interstitial fluid pressure will depend on the intracranial pressure. If these values are calculated from the present data it is apparent that there is a progressive increase in hydrostatic capillary pressure, which, although partly counterbalanced by the increase in interstitial fluid pressure would lead to an increase in net capillary filtration, if changes in colloid osmotic pressures can be neglected. Such changes offer an explanation of the progressive brain swelling which accompanies sustained intracranial hypertension.

As a compensatory mechanism there is, however, a change in the pressure differential, thought to control the transfer of CSF from subarachnoid space to venous sinus (Davson, 1967; Davson et al., 1970). Thus, in the present experiments, a progressive increase occurred in the pressure gradient between the subarachnoid space and the superior sagittal sinus. Even in those experiments where sagittal sinus pressure increased markedly, a significant gradient was still maintained in all but one instance.

In summary, therefore, a number of points emerge from the study of segmental pressure changes in the brain vasculature during raised intracranial pressure. It is clear, firstly, that a progressive increase in intracranial pressure will result in a similar increase in cortical vein pressure with the vein pressures staying slightly above the ambient intracranial pressure, thereby preserving the patency of the veins. In the majority of instances neither sagittal sinus nor jugular bulb pressures change appreciably, although sinus pressure may show a marked increase when intracranial pressure is raised by cisterna magna infusion. These findings mean that the current definition of cerebral perfusion pressure is valid, provided that the magnitude of the pressure drop between extracranial and intracranial arteries does not alter significantly as intracranial pressure is increased. A corollary of these findings is that there is a progressive increase in intracranial venous resistance with increasing intracranial pressure which is independent of the way in which the intracranial pressure is raised, but directly related to the level of pressure. The differences in blood flow seen with different types of intracranial hypertension depend, therefore, on variations in the response of the prevenous resistance, although the mechanism underlying such variations is not understood. The changes occurring in intravascular and extravascular pressures will also result in a net increase in transcapillary fluid movement from blood to brain, with increasing intracranial pressure. There will be, however, a compensatory increase in the pressure differential favouring transfer of CSF from subarachnoid space to venous sinus, as intracranial pressure is increased. 
Finally, from the clinician's standpoint, these findings establish the validity of the current definition of cerebral perfusion pressure, while at the same time showing that clinical measurements of intracranial perfusion pressure do not allow conclusions to be drawn about the level of cerebral blood flow in individual cases.

The authors wish to thank Professor W. B. Jennett and Dr. A. M. Harper for their advice and assistance throughout this study. Our thanks are also due to the technical staff of the Wellcome Surgical Research Institute.

\section{REFERENCES}

Becht, F. C. (1920). Studies on the cerebrospinal fluid. American Journal of Physiology, 51, 1-125.

Bedford, T. H. B. (1942). The effect of variations in the subarachnoid pressure on the venous pressure in the superior longitudinal sinus and in the torcular of the dog. Journal of Physiology, 101, 362-368.

Brown, F. K. (1956). Cardiovascular effects of acutely raised intracranial pressure. American Journal of Physiology, 185, 510-514.

Davson, H. (1967). The Physiology of the Cerebrospinal Fluid. Churchill: London.

Davson, H., Hollingsworth, G., and Segal, M. B. (1970). The mechanism of drainage of the cerebrospinal fluid. Brain, 93, 665-678.

Dixon, W. E., and Halliburton, W. D. (1914). The cerebrospinal fluid. II. Cerebro-spinal pressure. Journal of Physiology, 48, 128-153.

Green, H. D., Rapela, C. E., and Conrad, M. C. (1963). Resistance (conductance) and capacitance phenomena in terminal vascular beds. In Handbook of Physiology, pp. 935-960. Edited by E. F. Hamilton and P. Dow. Section 2, Circulation Vol. 2. American Physiological Society: Washington.

Häggendal, E., Löfgren, J., Nilsson, N. J., and Zwetnow, N. N. (1970). Effects of varied cerebrospinal fluid pressure on cerebral blood flow in dogs. Acta Physiologica Scandinavica, 79, 262-271.

Johnston, I. H., Rowan, J. O., Harper, A. M., and Jennett, W. B. (1972). Raised intracranial pressure and cerebral blood flow: I. Cisterna magna infusion in primates. Journal of Neurology, Neurosurgery, and Psychiatry, 35, 285-296.

Johnston, I. H., Rowan, J. O., Harper, A. M., and Jennett, W. B. (1973). Raised intracranial pressure and cerebral blood flow. 2. Supratentorial and infratentorial mass lesions in primates. Journal of Neurology, Neurosurgery, and Psychiatry, 36, 161-170.

Kanzow, E., and Dieckhoff, D. (1969). On the location of the vascular resistance in the cerebral circulation. In Cerebral
Blood Flow, pp. 96-97. Edited by M. Brock, C. Fieschi Z D. H. Ingvar, N. A. Lassen, and K. Schürmann. Springer Berlin.

Kety, S. S., Shenkin, H. A., and Schmidt, C. F. (1948). Thœ effects of increased intracranial pressure on cerebra $\bar{b}$ circulatory functions in man. Journal of Clinical Investigation, 27, 493-499.

Kinal, M. E. (1966). Infratentorial tumors and the durat venous sinuses. Journal of Neurosurgery, 25, 395-401.

Langfitt, T. W., Weinstein, J. D., Kassell, N. F., Gagliardi L. J., and Shapiro, H. M. (1966). Compression of cerebrak vessels by intracranial hypertension. I. Dural sinus pres $\Rightarrow$ sures. Acta Neurochirurgica, 15, 212-222.

Mellander, S., and Johansson, B. (1968). Control of resist=o ance, exchange, and capacitance functions in the periphera circulation. Pharmacological Reviews, 20, 117-196.

Miller, J. D., Stanek, A., and Langfitt, T. W. (1972). Con- $-\frac{\mathscr{S}}{}$ cepts of cerebral perfusion pressure and vascular compres- $\mathbb{Q}$ sion during intracranial hypertension. Progress in Braino Research, 35, 411-432.

Noell, W., and Schneider, M. (1948). Zur Häemodynamik $\overrightarrow{0}$ für der Gehirndurchblutung bei Liquordrucksteigerung: Archiv für Psychiatrie und Nervenkrankheilkunde, 118-180, 713-730.

Osterholm, J. L. (1970). Reaction of the cerebral venous sinus system to acute intracranial hypertension. Journal of Neurosurgery, 32, 654-659.

Pappenheimer, J. R., and Soto-Rivera, A. (1948). Effective $\omega$ osmotic pressure of the plasma proteins and other quan?i-i ties associated with the capillary circulation in the hireti limbs of cats and dogs. American Journal of Physiolog 152, 471-491.

Shulman, K. (1965). Small artery and vein pressures in subarachnoid space of the dog. Journal of Surgical Resears, $5,56-61$.

Shulman, K., and Verdier, G. R. (1967). Cerebral vascumir resistance changes in response to cerebrospinal fli $\mathrm{d}$ pressure. American Journal of Physiology, 213, 1084-10

Shulman, K., Yarnell, P., and Ransohoff, J. (1964). DuFril $A$ sinus pressure in normal and hydrocephalic dogs. Archive of Neurology, 10, 575-580.

Weed, L. H., and Flexner, L. B. (1933). The relations of the intracranial pressures. American Journal of Physiology, 105, 266-272.

Wegefarth, P. (1914). Studies on cerebro-spinal fluid. VI. The establishment of drainage of intra-ocular and intra- $\mathrm{Q}$ cranial fluids into the venous system. Journal of Medical Research, 31, 149-166.

Wright, R. D. (1938). Experimental observations on increased intracranial pressure. Australian and New Zealand Journal of Surgery, 7, 215-235.

Zwetnow, N. N. (1968). CBF autoregulation to bloodpressure and intracranial pressure variations. Scandinavian? Journal of Clinical and Laboratory Investigation, 22, Suppl.0 102, V:A.

Zwetnow, N. N. (1970). Effects of increased cerebrospinal fluid pressure on the blood flow and on the energy metabolism of the brain. An experimental study. Acta Physiologica Scandinavica, Suppl. 339. 